\title{
Testing the Efficacy of Synthetic Vision during Non-Normal Operations as an Enabling Technology for Equivalent Visual Operations
}

\author{
Lynda J. Kramer and Steven P. Williams \\ NASA Langley Research Center \\ Hampton, Virginia
}

\begin{abstract}
Synthetic Vision (SV) may serve as a revolutionary crew/vehicle interface enabling technology to meet the challenges of the Next Generation Air Transportation System Equivalent Visual Operations (EVO) concept - that is, the ability to achieve or even improve on the safety of Visual Flight Rules (VFR) operations, maintain the operational tempos of VFR, and potentially retain VFR procedures independent of actual weather and visibility conditions. One significant challenge lies in the definition of required equipage on the aircraft and on the airport to enable the EVO concept objective. An experiment was conducted to evaluate the effects of the presence or absence of SV, the location (head-up or head-down) of this information during an instrument approach, and the type of airport lighting information on landing minima. Another key element of the testing entailed investigating the pilot's awareness and reaction to non-normal events (i.e., failure conditions) that were unexpectedly introduced into the experiment. These non-normals are critical determinants in the underlying safety of all-weather operations. This paper presents the experimental results specific to pilot response to non-normal events using head-up and head-down synthetic vision displays.
\end{abstract}

\section{INTRODUCTION}

The Integrated Intelligent Flight Deck Technologies (IIFDT) project, under NASA's Aviation Safety Program, comprises a multi-disciplinary research effort to develop flight deck technologies that mitigate operator-, automation-, and environment-induced hazards. Towards this objective, IIFDT is developing crew/vehicle interface technologies that reduce the propensity for pilot error, minimize the risks associated with pilot error, and proactively overcome aircraft safety barriers that would otherwise constrain the full realization of the next generation air transportation system. Part of this research effort involves the use of enhanced and synthetic vision systems and other interface modalities as enabling technologies to meet the challenges of an Equivalent Visual Operations (EVO) concept - that is, the ability to achieve or even improve on the safety of Visual Flight Rules (VFR) operations, maintain the operational tempos of VFR, and even, perhaps, retain VFR procedures independent of actual weather and visibility conditions.

One significant challenge to the EVO concept objective is the definition of required equipage on the aircraft and on the airport. With today's equipment and regulations, significant investment is required in on-board equipment for navigation, surveillance, and flight control and on the airport for precision guidance systems and approach lighting systems for "allweather" landing capability. The levels of equipment redundancy, capability, and accuracy dramatically increase as landing visibility minima decrease. A vivid demonstration of the current complexity (and cost) to meet "weather and visibility-independent" capability is to look at the present National Air Space infrastructure. As of January 2008, there were 1,229 Instrument Landing System (ILS) instrument approach procedures (IAPs) to Category I minima (no lower than $200 \mathrm{ft}[61 \mathrm{~m}]$ decision height, $2400 \mathrm{ft}$ [731.5 m] visibility) available throughout the United States, but only 143 Category II (no lower than $100 \mathrm{ft}[30.5 \mathrm{~m}]$ decision height,
$1200 \mathrm{ft}$ [366 m] visibility) and 111 Category III (a decision height lower than $100 \mathrm{ft}$, or no decision height, or a runway visual range (RVR) less than $1200 \mathrm{ft}$ ) IAPs.

In conjunction with the ILS sophistication, approach lighting systems of increasing complexity are required as landing visibility minima decrease. Typical for Category I precision approaches is the MALSR (Medium Intensity Approach Lighting System with Runway Alignment Indicator Lights) approach lighting system (ALS) and for Category II/III instrument approaches, the ALSF-2 (High Intensity Approach Lighting System with Sequenced Flashing Lights). An ALS provides the visual information for runway alignment, height perception, roll guidance, and horizontal references. EVO implies "Category III" operations to all runway thresholds. Synthetic vision (SV) displays may be one of the crew/vehicle interface technologies that help achieve the realization of EVO.

$\mathrm{SV}$ is a computer-generated image of the external scene topography that is generated from aircraft attitude, highprecision navigation, and data of the terrain, obstacles, cultural features, and other required flight information. A synthetic vision system (SVS) enhances this basic functionality with real-time integrity to ensure the validity of the databases, perform obstacle detection and independent navigation accuracy verification, and provide traffic surveillance. Under NASA's Aviation Safety Program/Synthetic Vision Project (1999-2006), NASA and its industry partners developed and deployed SVS technologies for commercial and business aircraft which were shown to provide significant improvements in terrain awareness and reductions for the potential of Controlled-Flight-Into-Terrain incidents/accidents (Arthur, Prinzel, Kramer, Bailey, and Parrish, 2003; Schiefele, Howland, Maris, Pschierer, Wipplinger, and Meuter, 2005; Schnell, Theunissen, and Rademaker, 2005); improvements in flight technical error to meet Required Navigation Performance criteria (Kramer, 
Prinzel, Bailey, and Arthur, 2003); and improvements in situation awareness without concomitant increases in workload compared to current generation cockpit technologies (Kramer, Arthur, Bailey, and Prinzel, 2005). It has been hypothesized that the use of SV technologies on head-up and head-down displays can provide precision approach, landing, and taxi guidance for "all weather" capability to all runways without, perhaps, requiring extensive approach lighting systems, ground-based precision guidance systems such as the ILS, or other airport infrastructure.

An experiment was conducted to evaluate the effects of the presence or absence of Synthetic Vision, the location of this information during an instrument approach (i.e., on a Head-Up or Head-Down Primary Flight Display), and the type of airport lighting information on landing minima. A simulated Global Positioning System/Wide Area Augmentation System (GPS/WAAS) was used for approach guidance, instead of an ILS, and for the navigation component of the on-board SVS. The "operational considerations" evaluated under this effort included reduced visibility, decision altitudes, and airport approach lighting systems, for SVS-equipped and non-equipped aircraft. Another key element of the testing entailed investigating the pilot's awareness and reaction to non-normal events (i.e., failure conditions) that were unexpectedly introduced into the experiment. These non-normals are critical determinants in the underlying safety of all-weather operations.

The current paper documents the pilot decision-making process in the presence of non-normal conditions (failures and erroneous display information) during an approach.

\section{METHODOLOGY}

\section{Subjects}

Twenty-three pilots, representing seven airlines and the Federal Aviation Administration (FAA) Flight Standards and Transport Aircraft Certification Branches, participated in the experiment. All but three participants had previous experience flying Head-Up Displays (HUDs). The subjects had an average of 1231 hours of HUD flying experience and an average of 16.8 years and 14.2 years of commercial and military flying experience, respectively.

\section{Simulator}

The experiment was conducted in the Integration Flight Deck (IFD) simulation facility at NASA Langley Research Center. The IFD emulates a Boeing B-757-200 aircraft and provides a full-mission simulation capability. The collimated out-the-window (OTW) scene is produced by an Evans and Sutherland ESIG 4530 graphics system providing approximately 200 degrees horizontal by 40 degrees vertical field-of-view at 26 pixels per degree. The synthetic terrain database used in the SV display concepts was created from a $0.33 \operatorname{arcsec}(\sim 10$ meter post-spacing) Digital Elevation Model (DEM) of a $53 \times 57 \mathrm{nmi}(98 \times 106 \mathrm{~km})$ area centered around the Dallas- Ft. Worth International Airport (FAA identifier: DFW). The DEM was draped with elevation-based generic imagery. The evaluation pilot (EP) occupied the left seat, as the Pilot Flying. The left seat included an overhead HUD projection unit and a head-down research display (RD).

Head-up display. The HUD subtended approximately $26^{\circ}$ horizontal by $21^{\circ}$ vertical field of view (FOV). The FOV for the HUD SV (raster) image was fixed and could not be varied by the EP. The HUD presentation was written strictly in raster format from a video source (RS-343) input. The input consisted of a video mix of symbology and computergenerated scene imagery. The symbology included "haloing" to ensure that the symbology was highlighted against the scene imagery background. HUD brightness, contrast, and declutter controls were provided to the pilot. The SV imagery, when displayed, was drawn conformally.

Head-down research display: A head-down $\mathrm{RD}$ was installed over the normal instruments on the left hand side of the IFD cockpit. The RD used an 18.1 in. (46 cm) diagonal case containing two high brightness liquid crystal displays (LCDs). The two separate LCD panels, each with XGA (1024x768) resolution, rendered a Size D $(6.4$ in. [41.7 cm] square viewable area) primary flight display, PFD (left display), and navigation display, ND (right display). The RD covered the normal Boeing 757 captain's displays with the exception of the analog standby instruments (attitude direction indicator, airspeed, and altitude).

The PFD and ND closely resembled current transport aircraft equipage. The PFD had a $50^{\circ}$ horizontal by $50^{\circ}$ vertical FOV and was only modified from typical equipage to include a Flight Path Marker (FPM) and guidance cue. The PFD FPM and guidance cue were driven by algorithms identical to the HUD. The ND showed the DFW Runway 18 Right (18R) approach path, but it did not include any Enhanced Ground Proximity Warning System nor Traffic Alert and Collision Avoidance System information.

\section{Display Concepts}

Four display concepts (baseline and SV, either head-up or head-down) were evaluated while flying approaches to DFW Runway $18 \mathrm{R}$. The head-down navigation display format was invariant.

Head-up display concepts. Two HUD display concepts were tested, differing from each other only in the type of raster background (SV or none) presented. Standard HUD symbology enhanced with a runway outline was employed in both HUD concepts. Glideslope and localizer raw data indicators which included a deviation scale and angular deviation indication were provided. The path deviation indicators showed angular course deviation (i.e., glideslope and localizer-like) conditions by converting the linear path error data to angle errors and scaling in "dots." For this experiment, one dot vertical error was equivalent to 0.35 degrees and one dot lateral error was equivalent to 1.0 degrees. The altitude tape included a horizontal bar representing the current Decision Altitude (DA), and a barberpole presentation to indicate field elevation. A glideslope reference line was drawn at the DFW Runway 18R ILS 
descent angle of $3.0^{\circ}$. In Figure 1, the two HUD Concepts are shown - the Baseline HUD (left) and the SV HUD (right). During the HUD experimental runs, the "baseline" PFD was displayed (PFD format shown on the left side of Figure 2.).
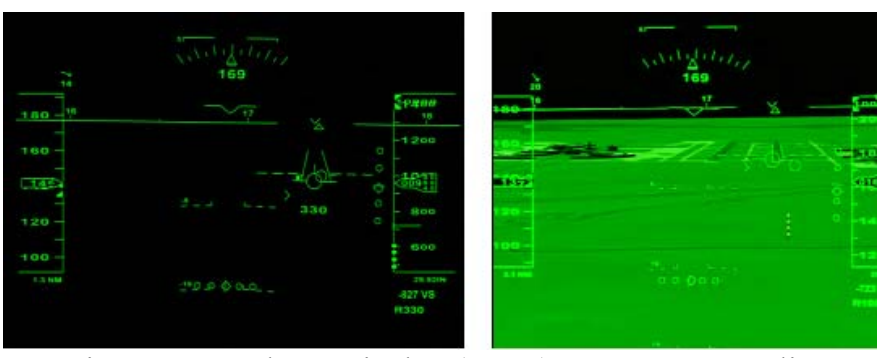

Figure 1. Head-Up Display (HUD) Formats - Baseline (left) and Synthetic Vision (right).

Head-down display concepts. Two PFD display concepts were tested, differing from each other only in the type of background (standard sky/ground or SV) presented with the flight symbology. Figure 2 presents the two PFD Concepts the Baseline PFD (left) and the Synthetic Vision PFD (right). Like the HUD, a glideslope reference line was drawn on the PFD at the DFW Runway 18R ILS descent angle of $3.0^{\circ}$. Unlike the HUD, the runway outline on the PFD was only drawn when the PFD background was synthetic vision, and the runway outline was drawn conformal in size to the selected runway and included an extended center line. For the head-down display evaluations, the HUD was stowed to preclude blocking or distortion of the pilot's forward view of the outside world.

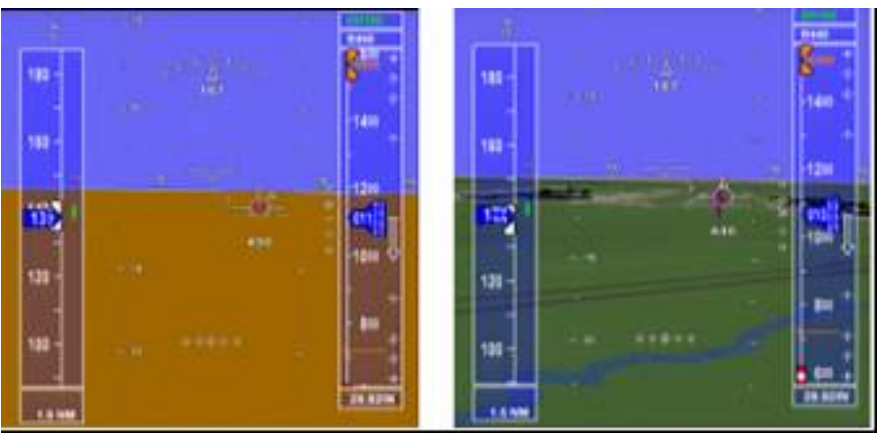

Figure 2. Primary Flight Display (PFD) Formats - Baseline (left) and Synthetic Vision (right).

\section{Approach Lighting System Configurations}

Three different ALS configurations were used for this experiment. The first ALS configuration (hereinafter referred to as the VFR ALS) was representative of lights found at a VFR runway and included Runway End Identification Lights (REIL), precision approach path indicator lights (PAPI), partial threshold lights, and medium intensity runway lights (MIRL). The second ALS configuration (hereinafter referred to as the MALSR ALS) was representative of a Category I/Type I operations runway and included MALSR, REIL, PAPI, full threshold lights, and MIRL. The third ALS configuration (hereinafter referred to as the ALSF-2 ALS) was representative of a standard Category II/Type II operations runway and included ALSF-2, touchdown zone and centerline lighting, REIL, PAPI, full threshold lights, and high intensity runway lights (HIRL).

\section{Evaluation Task}

The evaluation task was a straight-in GPS WAAS-type approach with a $3^{\circ}$ descent angle to Runway $18 \mathrm{R}$ at DFW airport. For each run, the approach started $5 \mathrm{~nm}(9260 \mathrm{~m})$ from the runway threshold and the aircraft was placed one dot left or right of the course centerline, and one dot high or low of the course glide path. The weather consisted of altitudebased cross winds (wind direction and intensity was dependent on altitude), light turbulence (root-mean-square of $2 \mathrm{ft} / \mathrm{s}[0.6 \mathrm{~m} / \mathrm{s}])$, and varying visibility levels $(2400 \mathrm{ft}, 1800 \mathrm{ft}$ [549 m], or $1200 \mathrm{ft}$ RVR). The wind profile started out as a 20 knot left or right quartering head-wind and reduced to a direct 10 knot cross-wind at field elevation. The evaluation pilot hand-flew the approach from the left seat with auto-throttles engaged at a speed of 138 knots. The run was terminated at full-stop or upon go-around initiation. The aircraft was configured to land prior to each run (landing gear down and flaps 30 degrees), and the aircraft was "Cleared to Land." There were no other aircraft in the environment, and there was no ATC involvement in the task.

Each approach had a DA of either $200 \mathrm{ft}$ or $100 \mathrm{ft}$. For the $200 \mathrm{ft}$ DA approaches, the evaluation pilot was required to visually acquire the approach lighting system by $200 \mathrm{ft}$ above the touchdown zone elevation (TDZE) or a go-around was required. If the approach lighting system was visually acquired by $200 \mathrm{ft}$ above the TDZE, then the pilot was cleared to continue the approach but he/she could not descend below $100 \mathrm{ft}$ above the TDZE unless the required runway visual references (as defined in Federal Aviation Regulation 91.175) were distinctly visible and identifiable by natural vision. For the $100 \mathrm{ft}$ DA approaches, the evaluation pilot had to visually acquire the required runway references (e.g., threshold lights) by $100 \mathrm{ft}$ above the TDZE in order to land. Otherwise, a missed approach was executed.

The evaluation pilots were instructed to fly the aircraft as if there were passengers aboard, fly the center of the approach path, and land as close as possible to the centerline and touchdown zone (1000 $\mathrm{ft}[305 \mathrm{~m}]$ from the runway threshold). After landing, they were to capture the center line and come to a complete stop on the runway. They were also instructed to initiate a go-around if the landing was not safe or there were any safety concerns during the approach.

\section{Experiment Matrix}

Nominally, ten training runs and fifty-three experimental runs were completed by the EP. The primary experiment matrix consisted of combinations (but not a full-factorial) of Display Concept (Baseline HDD, SV HDD, Baseline HUD, or SV HUD), ALS (VFR, MALSR, or ALSF-2), runway visibility range $(1200 \mathrm{ft}, 1800 \mathrm{ft}, 2400 \mathrm{ft}$ ), and DA (100 or $200 \mathrm{ft}$ ) as shown in Table 1.

A significant component of the test, in addition to the nominal runs, was the investigation of the ability of the EP to 
recognize and properly handle non-normal events. These nonnormal runs were injected into the test unbeknownst to the EPs. Seven non-normal runs were flown by each EP. The nonnormal runs were four navigation system error scenarios, two altimetry failure scenarios, and one SV obstacle placement error scenario. Each of the non-normal runs used the MALSR ALS with a $100 \mathrm{ft}$ DA and $2400 \mathrm{ft} \mathrm{RVR}$. The number of nonnormal scenarios was designed to avoid expectancy on the part of the flight crew (Foyle and Hooey, 2003). The navigation system error scenarios purposefully introduced either a lateral navigation solution error (40 m right) or an altitude navigation solution error $(50 \mathrm{ft}[15 \mathrm{~m}]$ low) with respect to the real runway. This error resulted in the synthetic vision terrain and guidance cue being misaligned from the ALS and actual runway environment. The altimetry failure scenario emulated a failure inhibiting the aural callouts and the display of radar altitude information and flare cue symbology to the pilot. The intent of this scenario was to assess the impact of the aural callouts and radar altitude display on the pilot's ability to be cognizant of the DA, make the appropriate pilot callouts (e.g., "lights", "landing" or "goaround"), and perform a safe approach and landing. In the SV obstacle placement error scenario, a water tower which was located 2 miles $(3.2 \mathrm{~km})$ from the runway threshold in the OTW view (present on every run), had its SV icon (representing the obstacle) erroneously placed only 1 mile (1.6 $\mathrm{km}$ ) from the runway threshold. This scenario results in a mismatch of the SV imagery with the OTW scene for the water tower obstacle and presents a prominent SV-depicted obstacle along the aircraft's flight path.

Table 1: Primary Experiment Matrix

\begin{tabular}{|cc|c|c|c|}
\hline Visibility & Decision Altitude & VFR & MALSR & ALSF-2 \\
\hline \hline $1200 R V R$ & $100 \mathrm{ft}$ & $\sqrt{ }$ & $\sqrt{ }$ & $\sqrt{ }$ \\
\cline { 2 - 5 } & $200 \mathrm{ft}$ & & $\sqrt{ }$ & \\
\hline $1800 R V R$ & $100 \mathrm{ft}$ & & $\sqrt{ }$ & \\
& $200 \mathrm{ft}$ & & $\sqrt{ }$ & \\
\hline $2400 R V R$ & $100 \mathrm{ft}$ & $\sqrt{ }$ & $\sqrt{ }$ & $\sqrt{ }$ \\
& $200 \mathrm{ft}$ & & $\sqrt{ }$ & \\
\hline
\end{tabular}

Note: the checked cases were evaluated for all four display concepts

\section{RESULTS}

Nominal run objective and subjective data analyses from the present study were previously reported (Kramer, Williams, and Bailey, 2008; Kramer, Williams, Bailey, and Glaab, 2007) and are summarized below.

- Addition of SV imagery on the head-up or head-down displays did not have an adverse affect on approach and landing performance, and was, in fact, the pilots preference due to the significant increases it provided in situation and spatial awareness (without any workload penalties).

- SV HUD was rated as providing the greatest situation awareness and lowest workload among the 4 concepts tested.
- For the visual portion of the flight maneuver (i.e., landing), RVR appeared to be the most significant influence on touchdown performance.

- Type of ALS did not appear to influence touchdown performance or approach path maintenance.

The next sections document the pilot's decision-making process when confronted with seven non-normal events (4 navigation system errors, 2 altimetry failures, and $1 \mathrm{SV}$ obstacle placement error) while using the MALSR ALS with a $100 \mathrm{ft} \mathrm{DA}$ and $2400 \mathrm{ft} \mathrm{RVR}$. Of particular relevance to this paper and the subsequent discussion of the EPs reaction to non-normal events is that all nominal approaches (92 total runs) flown in these same flight conditions (MALSR ALS, $100 \mathrm{ft}$ DA, $2400 \mathrm{ft}$ RVR) resulted in a landing (i.e., no missed approaches) (see Kramer et al., 2008).

\section{Lateral Navigation Error}

Each pilot experienced two runs with a lateral navigation position error ( $40 \mathrm{~m}$ right on breakout), each occurring with the same display location (head-up or head-down), but with one evaluation using the baseline information content and the other using the SV information content. For all pilots, 43 landings were made out of 46 approaches (93\%) despite the lateral position error. Of the three missed approaches flown, a go-around occurred for one Baseline HDD run, one SV HDD run, and one SV HUD run. With the Baseline HDD run, the pilot called "go-around" when he didn't think he had enough time to recover from the error. This same pilot also went around with the SV HDD run. On the SV HUD missed approach condition, the pilot called "go-around" and then post-run, commented that there must have been a lateral shift. To test the influence of a substantial lateral navigation error on touchdown performance, an ANOVA was performed on touchdown lateral position from centerline. The effects of run type (nominal, $40 \mathrm{~m}$ offset), $\mathrm{F}(1,21)=0.433, \mathrm{p}=0.52$, and display concept (SV HUD, Baseline HUD, SV HDD, Baseline HDD), $F(3,84)=0.445, p=0.72$, were not found to be significant for this measure. Run type means were $8 \mathrm{ft}(2.4 \mathrm{~m})$ for the nominal runs and $7 \mathrm{ft}(2.1 \mathrm{~m})$ for the 40 meter offset runs. Display type means were $9 \mathrm{ft}(2.7 \mathrm{~m})$ for the Baseline HDD and $8 \mathrm{ft}$ for the other three display concepts. Visual inspection of the landing data revealed that all touchdowns occurred on Runway 18R and ended safely with a full-stop. One could infer that the presence or absence of a 40 meter error did not affect the touchdown performance.

\section{Altitude Navigation Error}

Every pilot saw two altitude navigation error runs $(50 \mathrm{ft}$ low on breakout) during data collection, each happening at the same display location (head-up or head-down) with one using the baseline information content and the other using the SV information content. 44 of the $46(96 \%)$ altitude navigation error runs ended in a landing. A go-around occurred for one SV HDD run and one SV HUD run. On the SV HDD run, the pilot correctly followed pilot procedures and performed a goaround as he had the approach lights but not the runway environment through natural vision at $100 \mathrm{ft}$ TDZE. Hence, 
this go-around was not due to the altitude navigation error. On the SV HUD run, the pilot called go-around once he broke out and saw that he was low on the approach. The presence of a $50 \mathrm{ft}$ low altitude navigation solution error appears to not have adversely affected the missed approach rate $(2 \%$, or 1 out of 46 , with altitude error versus $0 \%$ with nominal runs) but it did affect touchdown performance. Visual inspection of the landing data revealed that two of the altitude navigation error landings occurred before reaching the Runway 18R threshold - one with the Baseline HUD (landed $39 \mathrm{ft}$ [11.9 m] aft of threshold) and one with the SV HUD (landed $102 \mathrm{ft}$ [31.1 m] aft of threshold). To test the influence of a significant altitude navigation error on touchdown performance, an ANOVA was performed on the touchdown longitudinal distance from aim point for the 42 landings that occurred on Runway 18R. There were no significant run type effects, $F(1,23)=0.434$, $\mathrm{p}=0.52$, or display type effects, $\mathrm{F}(3,74)=0.717, \mathrm{p}=0.55$, for this measure.

\section{Altimetry Failure}

Each pilot saw two altimetry failure runs during data collection, each happening at the same display location (headup or head-down) with one using the baseline information content and the other using the SV information content. Of the altimetry failure runs 45 of 46 ended in a landing. The one altimetry failure run that ended in a go-around was due to the pilot noticing that the Baseline HDD didn't have the radar altitude information and so he decided to go-around. The pilot commented that he had the lights required for landing. The presence of an altimetry failure did not appear to adversely affect the missed approach rate $(2 \%$ with altimetry failure versus $0 \%$ with nominal runs). ANOVAs were performed on touchdown lateral distance from centerline and longitudinal distance from aim point. There were no significant run type effects, $\mathrm{F}(1,21)=0.005$, $\mathrm{p}=0.94$, or display type effects, $\mathrm{F}(3,84)=0.633, \mathrm{p}=0.60$, for lateral distance from centerline. Similarly, no significant run type effects, $F(1,22)=1.068$, $\mathrm{p}=0.31$, or display type effects, $\mathrm{F}(3,86)=0.794, \mathrm{p}=0.50$, were found for longitudinal distance from aim point. All landings occurred on Runway $18 \mathrm{R}$ and safely ended in a full-stop.

\section{Obstacle Placement Error in SV Database}

Each pilot saw one SV obstacle placement error run during data collection. Twelve of the pilots encountered the SV obstacle placement error on the SV HDD concept and 11 of the pilots encountered the error on the SV HUD concept. During this run, 4 out of the 12 pilots (33\%) went around when using the SV HDD and 9 out of the 11 pilots $(82 \%)$ went around when using the SV HUD. During an approach, the SV obstacle icon misplacement was recognizable sooner on the HUD $(\sim 1700 \mathrm{ft}[518 \mathrm{~m}]$ mean sea level [MSL]) than on the HDD $(\sim 1200 \mathrm{ft}[366 \mathrm{~m}] \mathrm{MSL})$. The symbology and imagery on the HUD is conformal with the out-the-window view; while, the symbology and imagery on the HDD is minimized. In addition, the obstacle icon on the HDD was somewhat occluded by the magenta guidance cue and runway outline with extended centerline. For one of the HUD landings, post-run the pilot commented that he knew that the obstacle was in the approach path but he also knew that he was on glide path and so he just assumed something was being drawn incorrectly on the display. For the other HUD landing, the pilot commented post-run that at $320 \mathrm{ft}(98 \mathrm{~m})$ above ground level he noticed what he thought was an extended runway centerline. He didn't realize it was the obstacle icon that he was viewing as he had seen the real water tower OTW prior to this point in the approach. For one of the HDD landings, the pilot reported the tower OTW during the run and post-run commented that the icon was not drawn correctly with regard to the tower OTW. During one approach, a pilot commented on misplacement of the obstacle icon, leveled off momentarily, and then decided to continue the landing. Two pilots commented post-run that the water tower symbol seemed to "pop up" all of a sudden on the display and that it happened too suddenly to react to it. Four of the pilots made no comment at all on the SV obstacle placement error on the HDD.

\section{DISCUSSION}

Pilot decision-making and reaction to non-normal events such as a navigation solution error or an altimetry failure was not adversely affected by the addition of synthetic vision (SV) imagery on either the head-up or head-down displays. However, display minification negatively impacted pilot identification of an SV obstacle placement error within the imagery and subsequent recognition and reaction to it. Future research experiments should examine the feasibility of using vision technologies like synthetic and enhanced vision (e.g., for SV obstacle integrity checking and aim point verification) to provide for an all weather (visibility) landing capability without the need for a visual approach segment.

\section{REFERENCES}

Arthur, J. J., III, Prinzel, L. J., Kramer, L. J., Bailey, R. E., and Parrish, R. V. (2003). CFIT prevention using synthetic vision. Proceedings of SPIE, Enhanced and Synthetic Vision 2003, Volume 5018, 146-157.

Foyle, D. C. and Hooey, B. L. (2003). Improving evaluation and system design through the use of off-nominal testing: a methodology for scenario development. Proceedings of the 12th International Symposium on Aviation Psychology, pp. 397-402.

Kramer, L. J., Arthur, J. J., III, Bailey, R. E., and Prinzel, L. J., III. (2005). Flight testing an integrated synthetic vision system. Proceedings of SPIE, Enhanced and Synthetic Vision 2005, Volume 5802, 1-12.

Kramer, L. J., Prinzel, L. J., Bailey, R. E., and Arthur, J. J. (2003). Synthetic vision enhances situation awareness and RNP capabilities for terrainchallenged approaches. Proceedings of the American Institute of Aeronautics and Astronautics Third Aviation Technology, Integration, and Operations Technical Forum, AIAA 2003-6814, 1-11,

Kramer, L. J., Williams, S. P., and Bailey, R. E. (2008). Simulation evaluation of synthetic vision as an enabling technology for equivalent visual operations. Proceedings of SPIE, Enhanced and Synthetic Vision 2008, Volume 6957, Paper 19.

Kramer, L. J., Williams, S. P., Bailey, R. E., and Glaab, L. J. (2007). Synthetic vision systems - operational considerations simulation experiment. Proceedings of SPIE, Enhanced and Synthetic Vision 2007, Volume 6559, Paper 1.

Schiefele, J., Howland, D., Maris, J., Pschierer, C., Wipplinger, P., and Meuter, M. (2005) Human Factors Flight Trial Analysis for 3D SVS: Part II. In Proceedings of SPIE, Enhanced and Synthetic Vision 2005, Editor: Jacques G. Verly, Volume 5802, Paper 18, April 2005.

Schnell, T., Theunissen, E., and Rademaker, R. (2005) Human Factors Test \& Evaluation of an Integrated Synthetic Vision and Sensor-Based Flight 
Display System for Commercial and Military Applications. Paper presented at the NATO Research and Technology Organization, Human Factors and Medicine panel workshop entitled "Toward Recommended Methods for Testing and Evaluation of EV and E/SV-Based Visionic Devices", Williamsburg, VA, USA, 26-27 April 2005. 